\title{
Continuous improvement: a goal of New Year
}

Published online: 29 December 2015

(C) Springer Science+Business Media New York 2015

Greetings! Once again, the New Year has started quietly but steadily! It is the time when we can look back to our past year contemplating every success and failure committed. The objective of wishing a New Year is not only that we should have a new year. It is that we should have zeal and passion to make more improvements and learn from our mistakes to not to repeat, which is the part of continuous improvement at an individual as well as an organizational level.

A new year always brings new challenges, new goals, and new changes in one's life. It is the time for us to well plan our activities for continued success.

With the beginning of New Year, it gives me immense pleasure to report that Telecommunication Systems (TELS) is experiencing steady and healthy growth. The past year has been productive and exciting. Despite the large number of submissions, it remains our first priority to reduce the decision notification time with a quality peer-review process. We are trying our level best to maintain and further improve the rapid peer-review process to provide timely feedback to the submitting authors. Your support, as readers, authors, reviewers, editors, and board members, is much appreciated and critical to the continued success of TELS.

As we know that the topic of telecommunications is very wide and open and there are several new directions and emerging technologies under its umbrella. Consequently, TELS receives dozens of submissions, which have broad scope or focus on multidisciplinary topics of telecommunications. Therefore, sometimes it becomes quite hard for us to find appropriate editors and reviewers to perform a com- prehensive and rigorous peer-review process. Here, I would like to thanks the editorial board members for their help and action on the papers assigned to them.

The backlog of previously accepted papers is still a challenge for TELS. To tackle this challenge, we plan to publish more papers in each issue. But, for the journal's management, this decision is not quite easy due to its implications on the cost and probable decline in the yearly impact factor, etc. However, I would like to pay my appreciation to Springer and its staff who are very supportive to accept this request. Though impact factor of any journal is one of the metrics to judge its fame, but there are many other 'hidden factors' e.g. operations and restructuring, etc, which are performed internally by the journal's staff and board members and remain transparent to the readers. Certainly, it is a trade-off but quite hard to ignore. We always welcome suggestions from readers, advisory and editorial board members, and authors in improving the quality and contents of TELS.

Besides, please join me to welcome new advisory and editorial board members and pay gratitude to the members who resigned and left TELS in 2015. We certainly hope that our new members will have a significant positive impact on the image and standing of the journal. Let us continue working together in this exciting New Year, which I hope will be filled with success and happiness.

Muhammad Khurram Khan, Ph.D.

Editor-in-Chief

King Saud University, Saudi Arabia 